\title{
Impact of Total Innovation Management on Supply Chain in Nigeria's Automobile Industry
}

\author{
Dr. Olumuyiwa O. Olamade \\ National Centre for Technology Management (NACETEM), \\ Obafemi Awolowo University, Ile-Ife \\ Tel: +234-803-437-7130Ｅ-mail: muyiwaolamade@yahoo.com
}

Kazeem Abubakar (Corresponding author)

NACETEM, North-Central Zonal Office,

PMB 715, Abuja, Nigeria

Tel: +234-802-875-1764 E-mail: kz4tawa@gmail.com

\author{
Yusuff Shola .A \\ NACETEM, North-Central Zonal Office, \\ PMB 715, Abuja, Nigeria \\ Tel: +234-816-242-6085 E-mail: yusuffshola@yahoo.com
}

Doi:10.5296/jebi.v1i1.5595

URL: http://dx.doi.org/10.5296/jebi.v1i1.5595

\begin{abstract}
Total Innovation Management (TIM) is the system of forming an innovative synergy between technology, organization and culture to build innovation competence in organizations. Supply Chain (SC) is a global network used to deliver products and services from raw materials to end-customers via an engineered flow of information, physical distribution and cash. This paper appraised TIM on SC in the automobile industry in Nigeria using structured questionnaire and interview. The upshot indicated $40 \%$ of SC executives are more concerned with risk associated with supply and thus invest in insurance policies. $80 \%$ of trained SC staff applies ICT tools in visibility (trackability). All SC staff was receptive to innovative ideas, indicating sustainability of TIM ideology in the sector.
\end{abstract}

Keywords: Total Innovation Management, Supply Chain, automobile industry, Nigeria 


\section{Introduction}

Innovation can take several forms: in products, production processes or management systems. Innovating products is tied to $\mathrm{R} \& \mathrm{D}$ and consumer's needs and are oriented towards creation of products with higher performance. With the emphasis on environmental issues gaining ground, product innovation is aimed at generation of products that are environmentally friendly, efficient in energy usage, safe to operate and have larger links to social systems. On the other hand, innovating with processes relate to changes in machinery and other elements not directly related to employees and has the aim of increasing productivity (i.e. increasing quality and reducing costs). In the management angle, it has the aim of adapting these systems to new environmental conditions and improving the way in which people are managed and work organized. Innovation can be perceived as a critical aspect of technological catch-up even though it does not depend on inventions which are new to the world. It also occurs when a firm introduces a product or process to a country for the first time. It could be when other companies imitate pioneering firm. Likewise, when an initial or follower companies make minor improvements and adaptations to improve a product or production process, leading to productivity improvements (Egbetokun, 2010; Angel et al., 1999).

An innovative Supply Chain (SC) strive at putting in place an advanced human and mechanized management technology to facilitate timely receiving and delivery of orders while maintaining the minimal internal and external lead times. SAP (2012) viewed SC management is an integrating function with primary responsibility for linking major business functions and processes within and across companies into a cohesive and high-performing business model. It includes all logistics and management activities, as well as manufacturing operations, marketing, sales, product design, finance, and information technology. According to Patrick, (2008), SC management, virtual warehouses and e-procurement have the singular aim of reducing inventory cost and lead time. Martin et al., (2001) established that SC executives struggle with five primary challenges: visibility, risk, cost containment, customer demands and globalization. The scenario in automotive industry is further compounded by economic uncertainty, embryonic technologies and increasing customization. Industry experts have gone so far as to proclaim that the global business model for the automobile industry is broken.

TIM is the system of forming an innovative synergy among technology, organization and culture aimed at building up innovation competence for an organization (Zaipul, 2009). The APICS Dictionary, 10th Edition, defined SC as "the global network used to deliver products and services from raw materials to end-customers through an engineered flow of information, physical distribution, and cash." Integrated (an all-inclusive) SC management is gaining global recognition lately, especially in the auto assembly and the distributive trade industries. The string of innovations, especially incremental innovations, within the global network is the total innovation in the SC.

In Nigeria, the automobile sub-sector's share of GDP is over 10 percent as at 2011(Ad, 2001; NBS, 2011). Given the size of this sector and the huge growth potential projected for the sector, governments in Nigeria have instituted various programs aimed at revitalizing the sector. An extensive knowledge gap exists in innovative approaches to SC management 
aimed at improving the automobile sub-sector in Nigeria especially considering the emergence of TIM. There is no better time than now for companies in the sub sector to avail themselves of the opportunities provided by TIM to strike a balance between customer satisfaction and the pressure on the SC (Patrick, 2008; Chijioke, 2012).

This paper appraised the impact of TIM practices on the SC in the automobile industry of Nigeria with emphasis on the sales and maintenance sub sector. While the government is working with foreign investors to revive automobile assemble in the country, the sales and maintenance sub sector has been thriving accounting for more than $60 \%$ of activities in the sector. Considering the challenges of SC management, this paper sets out to answer the questions; are Nigerian companies in the automobile industry applying innovative approaches to their SC management as they balance lead time and customer satisfaction? What technologies do companies deploy to assure the quality of products before and after shipping, minimize costs, risks while products are in transit and meet or exceed customers' expectations? How are in-coming and out-going orders tracked? To what extent do companies synergize their innovative activities internally and externally? In Section 2, we discuss important literature that forms the intangible basis for the study. The scope and methodology are discussed in Section 3. Section 4 contains a discussion of the findings, and followed by conclusions and policy implications in Section 5.

\section{Conceptual Outline}

\subsection{Total Innovation Management}

In the same way many organizations recognized that the only way to make Total Quality Management (TQM) a reality is to engender a culture that made quality the concern of everyone. TIM is being recognized as a very modern and comprehensive innovation management style to entrench the culture of innovation in organizations (Dan, et al., 2009). Its emergence was tied to the "dilemma of technology innovation". The successful technology innovation should be an activity, including all the technological and non-technological factors in an organization (Bjorn, et al., 1997). TIM is the reinvention and management of an innovation value network that dynamically integrates the conception, strategy, technology (including IT base), structure and business process, culture, and people at all levels of an the organization. Xu et al., (2007) opined that the aim of TIM is to enhance the innovation competence of the company, create value for stakeholders, and sustain competitive advantage. Incorporating TIM in the SC is to innovate through the supply side. Suppliers have been known to be sources of great innovation ideas and of innovations that have positively influenced both products and processes resulting in maintaining or gaining market leadership in some industries. The development of strong partnership with suppliers facilitates open discussions about competitive business needs and helps to proffer innovative solutions. Thus a poorly managed SC may result in competitive disadvantage and loss of market presence. Authors have established that TIM goes beyond the synergistic linkage among all inherent elements and emphasizes that all employees are innovators and that innovation is realized in the totality of time/space of an enterprise. Total innovation occurs when a company benefits from a series of innovation occurring in other companies as a result of partnerships such as exists along the SC. 


\subsection{Supply Chain Management (SCM)}

\subsubsection{Concept of SCM}

The sequence of manufacturing and distribution cycle is known as SC. This could include activities from product design, materials and component ordering through manufacturing, assembling, to warehousing and distribution until the finished product is in the possession of the final consumer (William, 2004). A typical supply chain may include suppliers, manufacturers, distributors, retailers and customers (Ambe and Badenhorst-Weiss, 2010). The rapid evolution of the modern SCM has been enabled by the explosive development of information and communication technologies. Given the dynamics of the business environment which is now compounded by increasing globalization organizations may fail not because of bankruptcy, but because they run a poorly managed SC (Angel, et al., 1999).

Ambe and Badenhorst, (2010) held SCM is used interchangeably with logistics, while Martin, et al., (2001) saw it as the design and management of seamless, value-added process across organizational boundaries. SCM is more encompassing than logistics, since it captures the management of upstream and downstream relationships, while optimizing the system with customer service management, demand management, e-fulfillment, e-procurement and e-information (Cristina \& Helena 2007). Writers have expressed divergent opinions on the concept of SCM. For a fuller review see Burt, et al., (2010); Bjorn, et al., (1997).

Organizational inertia and difficulties of corporate culture change have been identified as key obstacles to SCM in most organizations as people operate (and think) in narrow, compartmentalized channels related to their field of specialty. To break this and implement horizontal structures, creating cross-functional teams remains one of the greatest difficulties confronting SCM (Martin, et al., 2001). Other challenges such as visibility, trackability of products in transit from the manufacturer to the final destination are also key to an innovative SC. To Hannu \& Rainer, (2003) visibility implies a clear view of upstream and downstream inventories, demand and supply conditions, and production and purchasing schedules, for instance. Visibility also covers internal visibility with clear lines of communications.

\subsection{Impact of TIM on SCM}

Deloitte (2009) argued that there is enormous pressure to reduce costs while increasing innovation, improving customer service, and responsiveness. To get around this challenge there are now available innovative modular software that helps in the transformation of a linear, sequential SC into a responsive supply network in which communities of customer-centric, demand-driven companies share knowledge, intelligently adapt to changing market conditions and proactively respond to demands. Networking capability, effectiveness of information fluidity, integration degree with the supplier's value chain, and integration degree with the customer's value chain are the intents of TIM in the SCM. Also, the use of a shared warehouse and online bidding is gradually gaining acceptance in SCM. What is fundamentally important is having a shared distribution linked back to production.

One way a company can access external knowledge is by engaging in inter-organizational strategic alliances as an important source of scientific and technological knowledge (Paul, et $a l ., 2011)$ Innovation may take place in the design of the kind of SC to be adopted, or at the 
process level deciding how parts of the designed SC will operate. Technology offers opportunities for either or both to be addressed, and SCs are changing as a result of technology adoption. This change has been noted to be slow in developing countries especially, where over-regulation and an unsupportive infrastructure hinder rather than facilitate SC management.

\subsection{Nigeria Automobile Industry; an Overview}

A historical account indicates that automobiles appeared on Nigerian roads in the 1920s and the country has since remained a veritable market for all kinds of automobiles, ranging from cars to vans and articulated trucks. Auto production, as part of a strategic national development plan of the government was not given a priority attention until the establishment of six assembly plants (two for cars and four for trucks) beginning with the establishment in 1975 of Peugeot Automobile Nigeria Limited (PAN), Kaduna. The other automobile assembly plants to follow were; Volkswagen of Nigeria Limited (VWON), Lagos; Anambra Motor Manufacturing Limited (ANAMMCO), Emene-Enugu in 1980; Steyr Nigeria Limited, Bauchi; National Truck Manufacturers (NTM, Kano); and Leyland Nigeria Limited, Ibadan (Moses, 2010).

The automobile industry is composed of various sections including, design, manufacture, assembly, sales and maintenance. The whole of the Nigerian auto industry is in a crisis phase except for the sales and maintenance sub sector, which is buoyed by the growing middle income class.. Like the moribund textile industry or the already comatose solid minerals and mining industry, the nation's automobile industry is virtually on the edge of a precipice waiting its eventual fall (SMJ, 2007; Chijioke, 2012). As accessed on Business-travel-Nigeria. com (2012), while the global economic meltdown has forced car sales to decline globally, the Nigerian auto sales has retained its lucrative status, still selling large units at attractive sales margins. In addition, sole distributorship arrangements exist with major car makers and their Nigerian partners. For instance, the BMW brand of cars is solely distributed in Nigeria by Coscharis. Toyota which is the leading car brand in Nigeria has Elizade Motors and Toyota Nigeria Ltd as its main distributors. Honda cars are distributed by Stallion Motors. Mitsubishi is distributed by CFAO Motors, while KIA is distributed by KIA Motors. Apart from the Peugeot Automobile Nigeria (PAN) Limited and perhaps the Anambra Motor Manufacturing Company Limited (ANAMMCO), all other hitherto known indigenous automobile manufacturing outfits such as Steyr and Volkswagen Nigeria Limited have long died. Efforts in recent times, especially of the current government under the economic transformation agenda has not yielded any noticeable outcome as these assembly plants still remain shut.

The six auto companies performed remarkably well in their first few years of operation. For instance, both PAN and VWON met the local demand for cars to a very considerable extent, while ANAMMCO with an installed capacity of 7,500 vehicles per annum (in a single shift) along with NTM and Steyr, could make about 50,000 trucks. The local industry then, had an installed capacity of 10,000 tractors per annum, Moses (2010). The boom lasted up till the mid-80s; PAN had local input manufacturers and suppliers in all parts of the country. Regrettably, a few years down the road, the industry began to witness a recession which was made worse by a series of unfavorable economic policies, especially the exchange rate regimes. 
Several causes have been identified by experts leading to the collapse of the industry. The leading cause has been the inadequate patronage of locally-assembled automobiles and lack of export outlets for automobiles assembled in Nigeria SMJ, (2007) cited most Nigerians' inability to afford them as a reason. Other challenges include poor capital base, high cost of production, poor performance of local content suppliers, poor operating environment, as well as obsolete technology. However, the maintenance sub sector supported by standardized automotive maintenance and service centres deploying modern technology and innovative driven SC strategy continue to blossom.

Recently as accessed on Vbulletin (2012) the Federal Government has announced plans to use the Central Bank of Nigeria (CBN) to invest the sum of $\$ 500$ billion aimed at revamping the industry. The funds will be targeted at getting the comatose automobile companies refitted and producing again. The challenges facing the automotive industry will require a major change in the business model Research Recap (2008) observed.

\section{Research Methodology}

Considering the peculiarity of the automobile industry in Nigeria, which is dominated by the sales and maintenance sector as the only vibrant arm, the impact of TIM on SC was concentrated in this area. For the purpose of this paper, a total of six major sales and maintenance outfits drawn from the six geo-political zones of the country were appraised. Questionnaires were administered in Bauchi (North East), Abuja (North Central), Kano (North West), Lagos (South West), Aba (South East) and Port Harcourt (South South). The main instrument was a structured questionnaire which addressed issues of visibility, risk and TIM adoption strategy. This was supplemented with additional information from the internet and face-to-face interview of executives and staff. The questionnaire was also geared towards assessing how TIM has been applied to mitigate the challenges SCM and especially the flow of information between and within suppliers and customers.

\section{Result and Discussion}

\subsection{Firm Structure}

For the purpose of this paper, a total of six (6) companies were sampled. Out of the six questionnaires administered, five (5) $83 \%$ were fully and appropriately completed. The sixth instrument was about $50 \%$ completed. In terms of ownership, Nigerians own $66.7 \%$ of the sampled organizations while $33.3 \%$ ownership belongs to foreign investors. To avoid an organization been tagged as local or foreign, $83.3 \%$ of respondents did not specify the nature of partnership with other SC members and nationality of foreign owners. Major activities undertaken by these companies include sales and maintenance of Toyota, Peugeot, BMW, Land Rovers, Ford, Honda, Audi, Volkswagen and Kia products as revealed by interviewed personnel and observation. The results of our analyses are displayed in Table 1.

\subsection{Incorporating Total Innovation Management in SCM}

TIM generates innovation synergy among technology, organization and culture and tends to reduce the impact of SC challenges on companies along the SC. Of the four challenges of the 
automobile industry challenges, risk was ranked topmost as it takes up $40 \%$ of the total challenges companies faced. This is however; lower than the $57 \%$ computed by a 2009 study conducted by the IBM. Other challenges were ranked equally at $20 \%$ each. In mitigating the challenges, companies adopt various technologies ranging from tracking devices to online tools. Nigerian companies mainly buy insurance cover as the predominant technology to mitigate SC challenges. $40 \%$ of mitigating measures goes to insurance covers reflecting the concern with risk as the major factor in SC challenges facing the companies. Tracking technology devices, networking and online devices associated with visibility of goods in transit ranked $20 \%$ each. This implies that Nigerian companies are more concerned with the safety of goods in transit than their ability to monitor and track the movement of goods in transit. Thus, investment in Internet facilities by companies may be limited to placing and receiving of orders and intra company communication than the more involving task of tacking shipments. This aspect of mitigating challenges of the SC appeared to have been transferred to the insurers. We hold that $80 \%$ adoption of the Internet to manage the visibility of goods in transit applied more to transit of goods within Nigeria than the transit of the goods from the country of origin to Nigeria which takes place largely (50\%) by sea. Considering that $70 \%$ of the lead time is lost at the Nigeria sea ports, $30 \%$ on roads, the deployment of the Internet is majorly to manage lead time lost and thus minimize cost. However, it can be inferred that innovative ideas and seamless information flow within and between supply and demand chain members which are key elements in TIM are observable in the industry.

To innovate is one thing; to have an integrated innovation managed system is another ball game. Though Egbetokun, et al., (2010), Roberto, et al., (2011) and other authors agreed it is always difficult measuring innovation as it is a tacit knowledge. TIM goes beyond managing product or process technology; it is an all-inclusive campaign. To achieve this, SC officers must be trained adequately to man the ever dynamic automobile industry whose business model must change over time as forecasted by Research Recap (2008). Innovating with TIM in the SC is a function, among others, of the readiness of companies to adopt TIM principles. While a greater percentage of companies $(60 \%)$ are not abreast with the application of TIM in the SC, an equal percentage (60\%) are ready to implement TIM practices in the SC. $20 \%$ are learning the ropes to implement TIM in their SC. This translates to $80 \%$ of the companies already implementing TIM in the SC in one form or the other. Interview with staff showed that $100 \%$ of the organizations welcome new ideas from staff on innovation and are ready to change, thus creating the enabling environment for innovation and implementation of TIM in the SC. Flexibility and participatory administrative structure may be a reflection of the qualifications of the SC executives. Our interview also revealed that staff in the service and maintenance workshops are familiar with technology enabled maintenance and supply requisition methods. 
Table 1: Result of Questionnaire Analysis on firm's TIM principles in SCM

\begin{tabular}{|c|c|c|c|c|c|}
\hline Ownership Structure of firm & $\% \mathbf{F}$ & Valid \% & Nature of Partnership & $\% \mathbf{F}$ & Valid \% \\
\hline Fully owned by Nigerian & 40.0 & 66.7 & Nigerian \& foreign individual & 10.0 & 16.7 \\
\hline Fully owned by foreign corporation & 20.0 & 33.3 & Not specified & 50.0 & 83.3 \\
\hline Total & 60.0 & 100.0 & Total & 60.0 & 100.0 \\
\hline \multicolumn{3}{|c|}{ Technology Available to improve SC } & \multicolumn{3}{|c|}{ Challenge in SC } \\
\hline Tracking Device & 10.0 & 20.0 & Visibility & 10.0 & 20.0 \\
\hline Networking & 10.0 & 20.0 & Risk & 20.0 & 40.0 \\
\hline Insurance & 20.0 & 40.0 & Customer demand & 10.0 & 20.0 \\
\hline Online & 10.0 & 20.0 & Others & 10.0 & 20.0 \\
\hline Total & 50.0 & 100.0 & Total & 50.0 & 100.0 \\
\hline \multicolumn{3}{|c|}{ Orders Visibility in organization } & \multicolumn{3}{|c|}{ IT tools application to TIM } \\
\hline Telephone & 10.0 & 20.0 & e-mail and World Wide Web & 20.0 & 40.0 \\
\hline Internet & 40.0 & 80.0 & Placing and Receiving orders & 30.0 & 60.0 \\
\hline Total & 50.0 & 100.0 & Total & 50.0 & 100.0 \\
\hline \multicolumn{3}{|c|}{ Awareness on TIM in SCM } & \multicolumn{3}{|c|}{ TIM practices in SCM } \\
\hline Yes & 20.0 & 40.0 & Ready to implement TIM & 30.0 & 60.0 \\
\hline No & 30.0 & 60.0 & Learning to implement TIM & 10.0 & 20.0 \\
\hline Total & 50.0 & 100.0 & Not ready to implement TIM & 10.0 & 20.0 \\
\hline \multicolumn{3}{|c|}{ Acceptance of innovative Ideas by companies } & Total & 50.0 & 100.0 \\
\hline Yes & 50.0 & 100.0 & & & \\
\hline \multirow{4}{*}{\multicolumn{3}{|c|}{ Conveyance method }} & Water & 30.0 & 50.0 \\
\hline & & & Air & 20.0 & 33.3 \\
\hline & & & Land & 10.0 & 16.7 \\
\hline & & & Total & 60.0 & 100.0 \\
\hline
\end{tabular}

Source: Survey, 2012

\section{Conclusion}

Our research on existing literature on the subject area have shown different approaches to defining and explaining the concept of TIM on SC as it concerns the automobile industry in general and Nigeria in particular. We equally agree with the submission of researchers on the subject area that TIM enhances the innovation competence of any practicing company, create value for stakeholders, and sustain competitive advantage. Impact of TIM on SC should reflect concern for innovative practices on every key element along the value chain involving suppliers, manufacturers, distributors, retailers and customers.

Considering the main focus of this paper which is to address issues of visibility, risk, TIM adoption strategy and how TIM has been applied to mitigate the challenges of information flow between and within suppliers and customers, it is logical to conclude based on our findings that companies are more concerned with the risk associated with the SC and therefore invest more in tracking technology and organization innovation among SC members. Tracking technology devices for visibility and monitoring supply is low. Hence, most companies invest more in insurance to protect their orders which are dominantly 


\section{MInstitute ${ }_{\text {Mnk }}^{\text {Macrothin }}$}

Journal of Entrepreneurship and Business Innovation ISSN 2332-8851

delivered from Germany, Korea, Japan, South Africa and France via sea transportation. However, it is encouraging that most companies are beginning to appreciate the impact of Technology (internet) in placing, tracking and receiving orders. Effort should be made to promote the practice of TIM in the industry as there is low synergy level in linking with SC members. Generally, the industry requires that management of companies needs to step up their game in building capacities of their SC officers in managing innovation. Likewise, government should strengthen policies that will promote TQM and TIM principles in managing the Nigeria sea ports in line with global best practices so as to open up the sector for more participation and leverage the latent competitive advantage that the country posses in terms of market and customer segment. In summary, automobile industry in Nigeria is dominated by sales and maintenance. TIM has a positive future impact on SCM in Nigerian automobile industry if well harnessed.

\section{Acknowledgement}

The research is financed by National Centre for Technology Management (NACETEM), North-Central Zonal Office, Abuja, Nigeria.

\section{References}

Ad R. V. (2001), Demand \& SC Management: A Logistical Challenge", Breukelen, the Netherlands, center for SC management, 17th international logistics congress, Thessaloniki [Online] Available:

http://vahabonline.com/wp-content/uploads/2013/11/vangoor-salonique.pdf (March 14, 2014) Ambe I. M. and Badenhorst-Weiss J. A. (2010), 'Strategic supply chain framework for the automotive Industry' African Journal of Business Management, 4(10), 2110-2120, 18 August, 2010, ISSN 1993-8233

Angel R. M., Frank D. \& Barrie G. D. (1999), “TQM and Business Innovation” [Online] Available: http://repositorio.bib.upct.es:8080/jspui/bitstream/10317/442/1/tqm3.pdf (March 14, 2014)

Bjorn A., Tom F., \& Stine R.(1997)," Benchmarking SC Management: Finding Best Practices", SINTEF Industrial Management, Trondheim, Norway, [Online] Available: http://www.prestasjonsledelse.net/publikasjoner/benchmarking\%20supply\%20chain\%20man agement.pdf (May 12, 2012)

Burt D. N., Petcavage, S. \& Pinkerton, R. (2010), Supply Management ( $8^{\text {th }}$ edition), Boston MA: Irwin McGraw-Hill

Business-travel-nigeria.com (2012). Business in Nigeria - Selling Cars, [Online] Available: http://www.business-travel-nigeria.com/business-in-nigeria-automobile.html (March 25, 2014) 


\section{Macrothink}

Journal of Entrepreneurship and Business Innovation ISSN 2332-8851 2014, Vol. 1, No. 1

Chijioke O. (2012), "Resuscitating the Automotive Industry in Nigeria", [Online] Available: http://businessdayonline.com/ng/index.php/analysis/features/36454-resuscitating-the-automot ive-industry-in-nigeria (March 15, 2014)

Cristina G. \& Helena R. L. (2007), 'e-Supply Chain Management: review, implications and directions for future research' journal of industrial engineering and management JIEM, 2011 - 4(2): 231-257, doi:10.3926/jiem.2011.v4n2.2013-0953

Dan C. B., Alexandru M., \& Ioan P. (2009), 'Critical aspects of the new paradigm of Total Innovation Management -On a procedure for the evaluation of the Innovative Potential' [Online]Available:

http://www.scribd.com/doc/16903464/Total-Innovation-Management-Dreng-Dan-C-Badea (March 12, 2014)

Deloitte T.T. (2009), A New Era; Accelerating Toward 2020 - an Automotive Industry Transformed [Online] Available:

https://www.deloitte.com/assets/Dcom-Panama/Local\%20Content/Articles/PA_es_A_NewEr a_12oct09.pdf (March 14, 2014)

Egbetokun A. A., Adeniyi A. A. \& Siyanbola W. O.(2010). Learning to Innovate in Nigeria's Cable and Wire Manufacturing Sub-Sector: Inferences from a Firm-Level Case Study, International Journal of Learning and Intellectual Capital 2010 - 7(1).55 - 74

Hannu V. \& Rainer B. (2003),"A Supply and Value Chain Management Methodology for the Internet Environment" Industrial Management Department, Tampere University of Technology at Pori

IBM (2009). The Smarter SC of the Future; Global Chief SC Officer Study, the Case for a Smarter Automotive SC" IBM Publications, GBE03220-USEN-00

IMS(2012), “SC Innovation”, [Online] Available:

http://www.ims-productivity.com/page.cfm/content/Supply-Chain-Innovation/ (March 23, 2014)

Infosys (2008),"Globalization Trends in SC ... Its Just Getting Riskier! Are we seeing a turn-around in SC thinking?", [Online] Available:

http://www.infosysblogs.com/supply-chain/2008/10/globalization_trends_in_supply.html/12 (March 23, 2014)

Martin C. et al. (2001). Supply Chain Strategy and Evaluation, first report, Sigma Project 2001.

Moses A. (2010), “Auto industry @ 50: So Far So Bad", [Online] Available: http://www.nigeriabestforum .com/ generaltopics (May 12, 2012) 


\section{I Macrothink}

Journal of Entrepreneurship and Business Innovation ISSN 2332-8851

NBS (National Bureau of Statistics) (2012), Distributive Trade and Services Industries, [Online] Available:http://www.nigerianstat.gov.ng/index.php/pages/sectorStatistics (February $14,2014)$

Paul A., Jan H. \& Pedro P. (2011), Individual scientific collaborations and firm-level innovation", Industrial and Corporate Change, 20(6), 1571-1599, doi:10.1093/icc/dtr030, (February 12, 2014)

Patrick P. (2008).Visibility within the SC., Whitman School of Management, Syracuse University, [Online]Available:

http://www.mhia.org/news/archive/7960/visibility-within-the-supply-chain (February 12, 2014)

Qingrui X., Ling Z. \& Zhangshu X. (2003), "Building Up Innovative Culture for Total Innovation Management", Engineering Management Conference, 2003. IEMC '03, 0-7803-8150-5

Research Recap (2008), “Auto Industry Business Model Needs a Major Overhaul”, [Online] Available:

http://seekingalpha.com/article/86818-auto-industry-business-model-needs-a-major-overhaul (March 14, 2014)

SAP: SC Management (2012)," Planning, Execution, and Collaboration across the Responsive Supply Network", [Online] Available: http://www.sap.com/solutions/business-suite/scm/index.epx (April 13, 2012)

S M J (2007), "Nigeria's automotive industry in decline", [Online] Available: http://allafrica.com/stories/ 200709240646.html (February 12, 2014)

Sonia G. \& Michael P. (2005), "Determining the Role of Innovation Management in Facilities Management" School of Built Environment, Liverpool John Moores University

VBulletin (2012), "Nigeria Automobile Industry Redemption Package”, [Online] Available: http://www.nigerianelitesforum.com/ng/transportation/8012-nigeria-automobile-industry-rede mption-package.html ( March 12, 2014)

William T.W (2004)," SC Architecture: A Blueprint for Networking the Flow of Material, Information, and Cash", the St. Lucie Series on Resource Management

Yu X. \& Thomas L.T, (2011) "Sustainability in SC Management: Suggestions for the Auto Industry", Journal of Management Decision, vol. 49 ISS: 4, pp.495 - 512

Xu, Q.R., Chen, J, Xie, Z.S., Liu, J., Zheng, G., Wang, Y. (2007). Total Innovation Management: a novel paradigm of innovation management in the 21 st century, Journal of Technology Transfer, 32(1-2), 9-25. 


\section{Macrothink}

Journal of Entrepreneurship and Business Innovation ISSN 2332-8851

Zaipul A. Z. (2009), "Total Innovation Management, A New Paradigm in Innovation Management", [Online] Available:

http://zaipul.wikispaces.com/file/detail/total+innovation+management.ppt_(March 12, 2014) 